\title{
Swertiamarin ameliorates carbon tetrachloride-induced hepatic apoptosis via blocking the PI3K/Akt pathway in rats
}

\author{
Qianrui Zhang ${ }^{1}$, Kang Chen ${ }^{2}$, Tao $\mathrm{Wu}^{3, *}$, and Hongping Song ${ }^{3, *}$ \\ 'Department of Pharmacy, General Hospital of the Yangtze River Shipping, Wuhan 430022, ${ }^{2}$ Department of Pharmacy, Huanggang Central Hospital, Huang- \\ gang 438000, ${ }^{3}$ Department of Pharmacy, Wuhan NO.4 Hospital, Wuhan Puai Hospital, Tongji Medical College, Huazhong University of Science and Technol- \\ ogy, Wuhan 430030, China
}

\section{ARTICLE INFO}

Received October 17, 2016

Revised April 4, 2018

Accepted June 1, 2018

*Correspondence

Hongping Song

E-mail: goodgravity@foxmail.com

Tao Wu

E-mail:hydrinsk@sina.com

\section{Key Words}

Akt

Carbon tetrachloride

Collagen

Hepatocyte apoptosis

Swertiamarin
ABSTRACT Swertiamarin (STM) is an iridoid compound that is present in the Gentianaceae swertia genus. Here we investigated antiapoptotic effects of STM on carbon tetrachloride $\left(\mathrm{CCl}_{4}\right)$-induced liver injury and its possible mechanisms. Adult male Sprague Dawley rats were randomly divided into a control group, an STM $200 \mathrm{mg} / \mathrm{kg}$ group, a $\mathrm{CCl}_{4}$ group, a $\mathrm{CCl}_{4}+\mathrm{STM} 100 \mathrm{mg} / \mathrm{kg}$ group, and a $\mathrm{CCl}_{4}+\mathrm{STM} 200 \mathrm{mg} / \mathrm{kg}$ group. Rats in experimental groups were subcutaneously injected with $40 \% \mathrm{CCl}_{4}$ twice weekly for 8 weeks. STM (100 and $200 \mathrm{mg} / \mathrm{kg}$ per day) was orally given to experimental rats by gavage for 8 consecutive weeks. Hepatocyte apoptosis was determined by TUNEL assay and the expression levels of $\mathrm{Bcl}-2$, Bax, and cleaved caspase- 3 proteins were evaluated by western blot analysis. The expression of TGF- $\beta 1$, collagen I, collagen III, CTGF and fibronectin mRNA were estimated by qRT-PCR. The results showed that STM significantly reduced the number of TUNEL-positive cells compared with the $\mathrm{CCl}_{4}$ group. The levels of Bax and cleaved caspase- 3 proteins, and TGF- $\beta 1$, collagen I, collagen III, CTGF, and fibronectin mRNA were significantly reduced by STM compared with the $\mathrm{CCl}_{4}$ group. In addition, STM markedly abrogated the repression of $\mathrm{BCl}-2$ by $\mathrm{CCl}_{4}$. STM also attenuated the activation of the PI3K/Akt pathway in the liver. These results suggested that STM ameliorated $\mathrm{CCl}_{4}$-induced hepatocyte apoptosis in rats.

\section{INTRODUCTION}

Liver fibrosis is part of the general wound-healing response to liver injury of various origins and is defined by the accumulation of and qualitative changes in extracellular matrix (ECM) components [1]. Following liver injury, two distinct paths are involved in the repair process: one is a regenerative path, in which the same type of cells replace injured cells; and the other paths is known as fibroplasia or fibrosis, in which normal parenchymal tissue is replaced by connective tissue in an uncontrolled manner [2]. The fibrosis is characterized by an imbalance between synthesis and degradation of the ECM, which is rich in fibrillar collagens (mainly collagens I and III). It was demonstrated that activated hepatic stellate cells (HSCs) are the main fibrogenic cells in the injured liver [3]. Following acute or chronic liver diseases, HSCs undergo phenotypic changes, switching from a quiescent vitamin A-rich phenotype to a myofibroblastic phenotype (activated HSC) [4]. Transforming growth factor beta-1 (TGF- $\beta 1$ ) has been identified as the most profibrotic cytokine, and can elevate the expression of collagen I in HSCs and promote their transition to a myofibroblast-like phenotype $[5,6]$.

The response to chronic liver injury also includes apoptosis and/or necrosis of parenchymal cells and their replacement by ECM, thus inducing liver fibrosis [7]. Hepatocyte apoptosis and liver fibrosis are major features of a wide range of chronic liver injuries [8]. Apoptosis is a genetically encoded form of cell suicide 
that plays a crucial role in the control of normal development and in the regulation of tissue homeostasis $[9,10]$. The activation of endonucleases and specific proteases (such as caspases) has been supposed to be the key mechanism of apoptosis. In caspasedependent apoptosis, cytochrome $\mathrm{c}$ redistributes from mitochondria to cytoplasm, which activates caspase- 9 and subsequently activates caspase-3 in concert with the cytosolic factor Apaf-1 [11,12]. There are alternative pathways defined as caspase-independent cell death. Recent advances have revealed that mitochondria play an important role via the release of proapoptotic proteins in caspase-independent pathway [13].

Carbon tetrachloride $\left(\mathrm{CCl}_{4}\right)$ is a well-known hepatotoxin used extensively in the study of hepatotoxicity in animal models. Because the pathological lesions developed in $\mathrm{CCl}_{4}$-treated rats and mice closely resemble the symptoms of liver cirrhosis in humans, this agent serves as an excellent model for determining mechanisms of fibrosis and for evaluating the efficacies of novel hepatoprotectants $[14,15]$.

Swertiamarin (STM) is a natural iridoid isolated from Swertia mussotii Franch (Gentianaceae) exerting predominant hepatoprotective activity [16]. We have previously demonstrated that STM could attenuate experimental fibrosis [17]. In this study, we aimed to explore the effects of STM on $\mathrm{CCl}_{4}$-induced hepatocyte apoptosis.

\section{METHODS}

\section{Chemicals and reagents}

Swertiamarin (purity $>98 \%$, dissolved in $1 \%$ Tween-20 saline) was provided by Xi'an Jiatian Biotechnology Co., Ltd (Xi'an, China). $\mathrm{CCl}_{4}$ was purchased from Sinopharm Chemical Reagent Co., Ltd (Shanghai, China). Anti-Bcl-2, anti-Bax, and anti-GAPDH antibodies were purchased from Santa Cruz Biotechnology Inc (Santa Cruz, California, USA). Anticleaved caspase-3 antibody was purchased from Cell Signaling Technology Inc (Danvers, Massachusetts, USA). The primary antibodies against phosphoPI3K, PI3K, phosphoAkt, and Akt were purchased from Cell Signaling Technology. LY294002 (PI3K inhibitor) was purchased from Santa Cruz Biotechnology (purity $\geq 98 \%$ ).

\section{Animals and groups}

This study was carried out in strict accordance with the guideline of the Council on Animal Care of Academia Sinica. The protocol was approved by the Ethical Committee on Animal Experimentation of Puai Hospital, Huazhong University of Science and Technology, China (Approval No. PAH2015-12). Adult male Sprague Dawley rats weighing 250-280 g were obtained from the Center of Experimental Animal of Hubei Province (Wuhan, China). All animals were kept under the same laboratory conditions of temperature $\left(25 \pm 2^{\circ} \mathrm{C}\right)$ and lighting (12:12 h light:dark cycle), and were given free access to standard laboratory chow and tap water. All rats were allowed to acclimatize for 1 week before the start of the experiment.

The animals were randomly assigned into six groups $(n=12)$ : control group rats were given $1 \%$ Tween- 20 saline by gavage once per day for 8 consecutive weeks with coadministration of vehicle (peanut oil, solvent of Carbon tetrachloride, $0.3 \mathrm{ml} / 100 \mathrm{~g}$, s. c. twice a week); STM $200 \mathrm{mg} / \mathrm{kg}$ group, rats were given STM dissolved in $1 \%$ Tween-20 saline $(200 \mathrm{mg} / \mathrm{kg} \mathrm{B.W.)} \mathrm{by} \mathrm{gavage} \mathrm{once}$ per day for consecutive eight weeks with coadministration of vehicle (peanut oil, solvent of $\mathrm{CCl}_{4}, 0.3 \mathrm{ml} / 100 \mathrm{~g}$, subcutaneously twice a week); $\mathrm{CCl}_{4}$ group rats were given $1 \%$ Tween- 20 saline by gavage once per day for 8 consecutive weeks with coadministration of $40 \% \mathrm{CCl}_{4}$ mixed peanut oil solution $(0.3 \mathrm{ml} / 100 \mathrm{~g}$, subcutaneously twice a week); $\mathrm{CCl}_{4}+\mathrm{LY} 294002$ group, rats were treated with LY294002 (0.3 mg/kg B.W., i.p.) at 2-day intervals for 8 consecutive weeks with coadministration of $40 \% \mathrm{CCl}_{4}$ mixed peanut oil solution ( $0.3 \mathrm{ml} / 100 \mathrm{~g}$, s.c. twice a week); $\mathrm{CCl}_{4}+\mathrm{STM} 100 \mathrm{mg} /$ $\mathrm{kg}$ group rats were treated with STM dissolved in 1\% Tween-20 saline (100 mg/kg B.W.) by gavage once per day for 8 consecutive weeks with coadministration of $40 \% \mathrm{CCl}_{4}$ mixed peanut oil solution $\left(0.3 \mathrm{ml} / 100 \mathrm{~g}\right.$, s.c. twice a week); $\mathrm{CCl}_{4}+\mathrm{STM} 200 \mathrm{mg} / \mathrm{kg}$ group rats were treated with STM dissolved in 1\% Tween-20 saline (200 $\mathrm{mg} / \mathrm{kg}$ B.W.) by gavage once per day for 8 consecutive weeks with coadministration of $40 \% \mathrm{CCl}_{4}$ mixed peanut oil solution $(0.3$ $\mathrm{ml} / 100 \mathrm{~g}$, s.c. twice a week).

Rats were fasted for $12 \mathrm{~h}$ after the last dose of agents before they were anesthetized with urethane $(1 \mathrm{~g} / \mathrm{kg}$ body weight, intraperitoneally). Blood samples were collected from the abdominal aorta for the assays of serum enzymes. The livers were removed and used for histological assessment and the measurements of protein expression, respectively. The livers were stored at $-80^{\circ} \mathrm{C}$ until use.

\section{Quantitative real-time PCR}

Expression of TGF- $\beta 1$, collagen I, collagen III, CTGF and Fibronectin were detected by quantitative real-time PCR (qRT-PCR). RNA was extracted from liver samples using TRIzol (Invitrogen, Carlsbad, CA, USA) according to standard protocol. Complementary DNA (cDNA) was produced by using the SuperScript Preamplification System for first-standing cDNA synthesis. qRTPCR was performed on cDNA samples using the MiniOpticom RT-PCR System (Bio-Rad Laboratories, Hercules, CA, USA) using the following sense and antisense primers: TGF- $\beta 1,5$ 'ctttaggaaggacctgggttg-3' and 5'-ggttgtgttggttgtagaggg-3'; collagen I, 5'-caggttgcagccttggttagg-3' and 5'-agaggcataaagggtcatcgtg-3'; collagen III, 5'-cattgcgtccatcaaagcctc-3' and 5'-gtcggaggaatgggtggctat-3'; CTGF, 5'-ccaactatgatgcgagccaact-3' and 5'-ttagcccggtaggtcttcacact-3'; Fibronectin, 5'-tacattcggcaggtatggtcttg-3' and 5'ttaccettccacaccccaatct-3'; GAPDH, 5'-ttcctacccccaatgtatccg-3' and 5'-catgaggtccaccaccctgtt-3'. The amplified product size by 
each pair of primers was $140,540,322,272,248$, and 281 bp for TGF- $\beta 1$, collagen I, collagen III, CTGF, fibronectin, and GAPDH respectively. The relative mRNA expression level was determined by calculating the values of $\Delta$ cycle threshold $(\Delta \mathrm{Ct})$ by normalizing the average $\mathrm{Ct}$ value compared with its endogenous control (GAPDH) and then calculating $2^{-\Delta \Lambda C t}$ values.

\section{TUNEL assay}

To quantify the hepatocellular apoptosis, the level of DNA fragmentation was detected using a TUNEL assay, which was performed according to the manufacturer's instructions (ApopTag Peroxidase In Situ Apoptosis Detection Kit; Chemicon, Billerica,
MA, USA). Ten microscopic fields within the view were randomly selected, and the TUNEL-positive cells were counted. The extent of damage was evaluated using the average number of positive cells.

\section{Western blot analysis}

The whole liver lysate was prepared to evaluate the expression level of Bcl-2, Bax, and cleaved caspase-3. The protein concentration was determined using the bicinchoninic acid assay and samples were stored at $-80^{\circ} \mathrm{C}$. Equal amounts of protein were separated with $10 \%$ sodium dodecyl sulfate-polyacrylamide gel electrophoresis. After electrophoresis, the gels were transferred
A

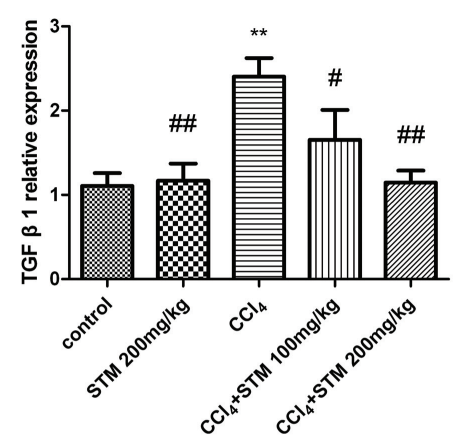

C

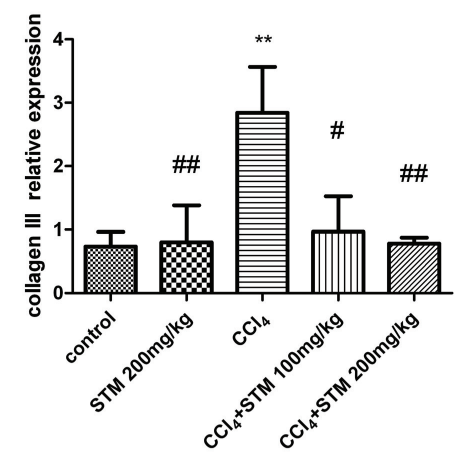

$\mathbf{E}$

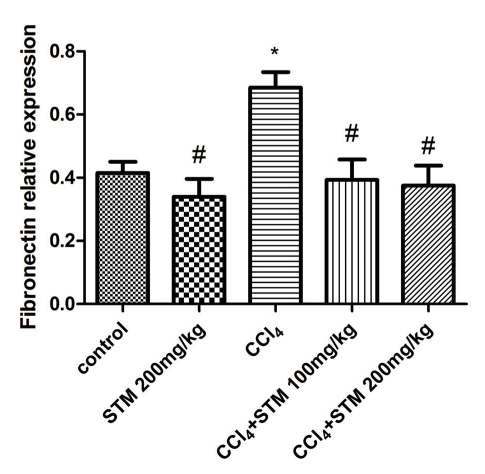

B

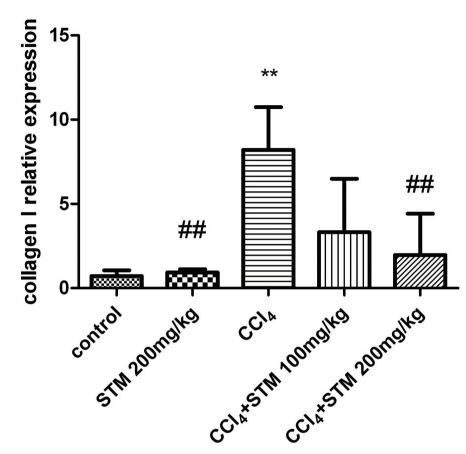

D

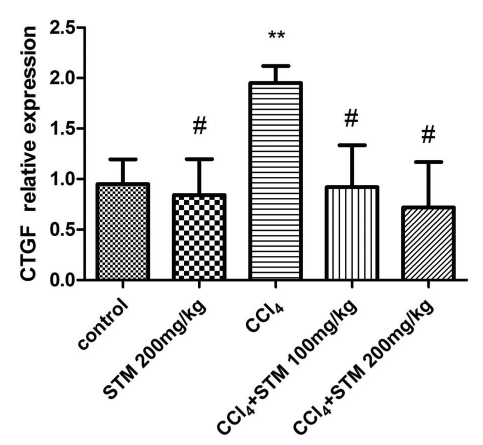

Fig. 1. Effects of STM on hepatic fibrotic genes mRNA expression in $\mathrm{CCl}_{4}$-induced rat liver. The mRNA expression of TGF- $\beta 1$, collagen I, collagen III, CTGF, and fibronectin was significantly increased following 8 weeks of chronic $\mathrm{CCl}_{4}$ exposure compared with the control group. STM (100 and $200 \mathrm{mg} / \mathrm{kg}$ ) treatment obviously decreased the mRNA expression of TGF- $\beta 1$, collagen I, collagen III, CTGF, and fibronectin compared with the $\mathrm{CCl}_{4}$ group (A-E). Data are represented as means \pm S.D. for 3-4 animals per group. ${ }^{*} p<0.05$ vs. control, ${ }^{* *} p<0.01$ vs. control; " $\mathrm{p}<0.05$ vs. $\mathrm{CCl}_{4}, \# \mathrm{p}<0.01$ vs. $\mathrm{CCl}_{4}$ by oneway ANOVA and LSD post hoc test. 
onto polyvinylidene difluoride membranes, which were blocked with Tris-buffered saline containing $5 \%$ nonfat milk at $4^{\circ} \mathrm{C}$. Next, the membranes were incubated overnight at $4^{\circ} \mathrm{C}$ in solution containing $0.1 \%$ Tween $20,5 \%$ nonfat milk, and the following primary antibodies: Bcl-2 (1:500); Bax (1:500); cleaved caspase-3 (1:1000); phosphoPI3K (1:1000); PI3K (1:1000); phosphoAkt (1:1000); Akt (1:1000); GAPDH (1:20000). After three washes in Tris-buffered saline Tween 20, the membranes were incubated with HRPconjugated secondary antibodies for $2 \mathrm{~h}$ at room temperature and subsequently processed for enhanced chemiluminescence (ECL) detection using potent ECL kit (Multisciences, China) and a chemiluminescence detection system (IS4000MM Pro, Kodak, USA). GAPDH was used as an internal index.

\section{Statistics}

Data were expressed as mean \pm S.D. The significant differences between groups were assessed with SPSS version 13.0. The differences between group means were calculated by one-way ANOVA with LSD post hoc analysis. Difference was considered statistically significant with a value of $\mathrm{p}<0.05$, and extremely significant with a value of $\mathrm{p}<0.01$.

\section{RESULTS}

\section{Effects of STM on hepatic fibrotic genes mRNA expression in $\mathrm{CCl}_{4}$-induced rat liver}

The mRNA expression of fibrotic genes such as TGF- $\beta 1$, collagen I, collagen III, CTGF, and fibronectin in the hepatic tissues were significantly increased following 8 weeks of chronic $\mathrm{CCl}_{4}$ exposure compared with the control group. STM (100 and $200 \mathrm{mg} /$ $\mathrm{kg}$ ) treatment obviously decreased the mRNA expression of TGF$\beta 1$, collagen I, collagen III, CTGF, and fibronectin compared with the $\mathrm{CCl}_{4}$ group (Figs. 1A-E).
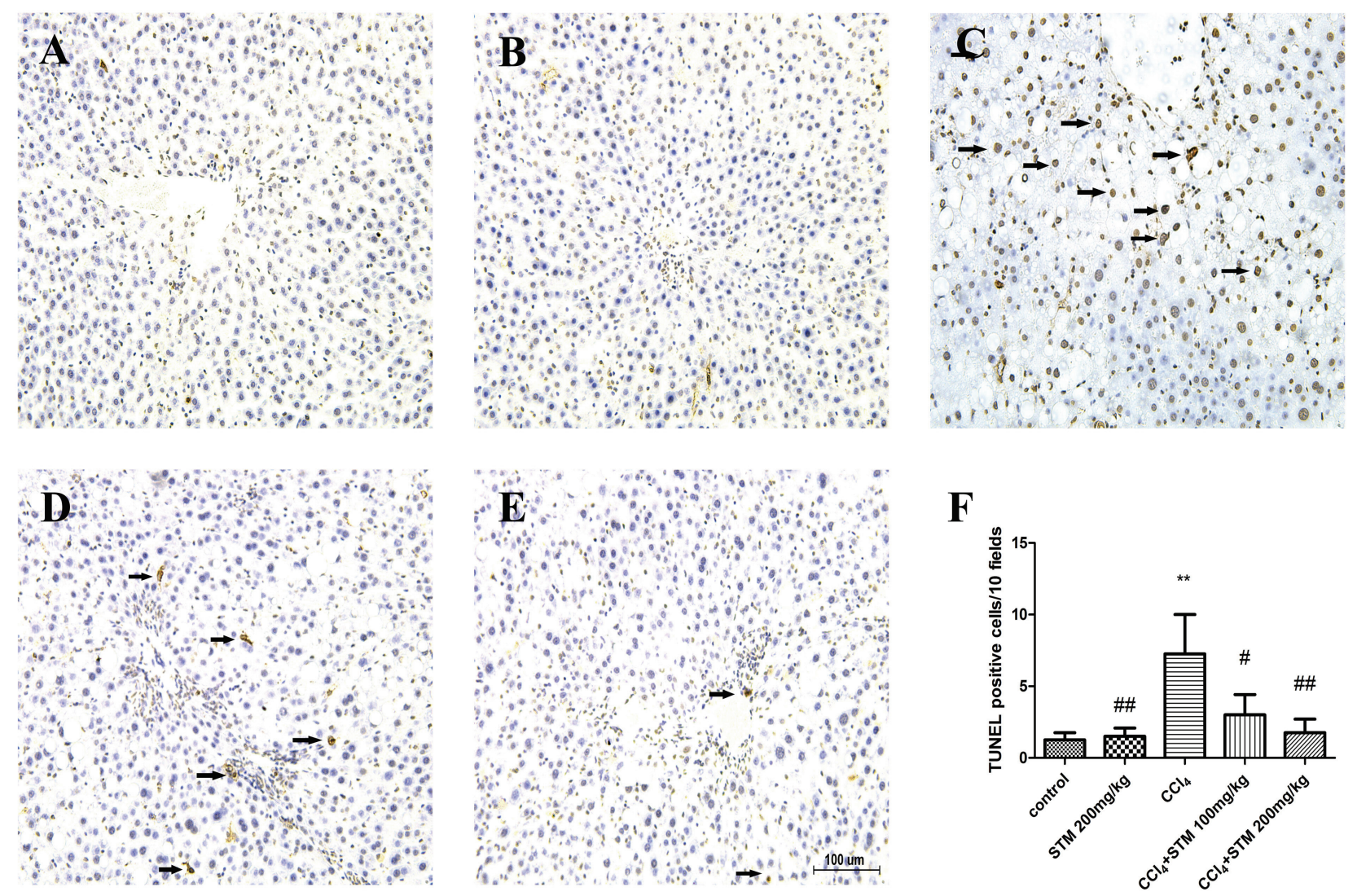

\section{$\times 200$}

Fig. 2. Effects of STM on hepatic apoptosis in $\mathrm{CCl}_{4}$-induced rat liver were detected by TUNEL assay. Representative photographs of TUNEL assay performed on liver sections of (A) control, (B) STM $200 \mathrm{mg} / \mathrm{kg}$, (C) CCl ${ }_{4}$ (D) CCl $\mathrm{Cl}_{4}+\mathrm{STM} 100 \mathrm{mg} / \mathrm{kg}$, (E) $\mathrm{CCl}_{4}+\mathrm{STM}_{2} 200 \mathrm{mg} / \mathrm{kg}$. The black arrows point to the apoptotic cells (TUNEL-positive cells) (magnification $\times 200$ ). (F) The bar graphs show the total number of TUNEL-positive cells/10 fields in liver sections of control, STM $200 \mathrm{mg} / \mathrm{kg}, \mathrm{CCl}_{4}, \mathrm{CCl}_{4}+\mathrm{STM}$-treated rats. Data are represented as means \pm S.D. for $3-4$ animals per group. ${ }^{*} p<0.05$ vs. control, ${ }^{* *} \mathrm{p}<0.01$ vs. control; ${ }^{\mathrm{p}} \mathrm{p}<0.05$ vs. $\mathrm{CCl}_{4},{ }^{\#} \mathrm{p}<0.01$ vs. $\mathrm{CCl}_{4}$ by one-way ANOVA and LSD post hoc test. 


\section{STM attenuated $\mathrm{CCl}_{4}$-induced hepatocyte apoptosis}

The control and STM $200 \mathrm{mg} / \mathrm{kg}$ groups showed few apoptotic hepatic cells (Figs. 2A and B). The number of TUNEL-positive cells increased significantly in the $\mathrm{CCl}_{4}$ group compared to that in the control group (Fig. 2C). In addition, the number of TUNELpositive cells in the $\mathrm{CCl}_{4}+\mathrm{STM}$ groups decreased significantly compared to that in the $\mathrm{CCl}_{4}$ group (Figs. 2D-F).

\section{Effects of STM on the expression of Bcl-2, Bax, and cleaved caspase-3 proteins}

The expression of Bax and cleaved caspase-3 protein were markedly increased following $\mathrm{CCl}_{4}$ treatment. STM treatment reduced the expression of $\mathrm{Bax}$ and cleaved caspase-3 protein significantly compared with the $\mathrm{CCl}_{4}$ group. In addition, $\mathrm{CCl}_{4}$ treatment also obviously reduced the expression of $\mathrm{Bcl}-2$ protein compared with the control group. In $\mathrm{CCl}_{4}+\mathrm{STM}$ groups, $\mathrm{Bcl}-2$ protein expression was increased notably compared with the $\mathrm{CCl}_{4}$ group (Fig. 3).

\section{STM inhibits hepatocyte apoptosis by blocking the activation of the PI3K/Akt pathway}

$\mathrm{CCl}_{4}$ treatment notably elevated the ratio of $\mathrm{pAkt} /$ Akt in rat liver as compared with the control group. Also, $\mathrm{CCl}_{4}$ treatment increased the ratio of $\mathrm{pPI} 3 \mathrm{~K} / \mathrm{PI} 3 \mathrm{~K}$ as compared with the control group. In $\mathrm{CCl}_{4}+\mathrm{STM}$ groups, STM markedly reduced the expression of pAkt/ Akt and pPI3K/PI3K as compared with the $\mathrm{CCl}_{4}$ group, suggesting the blocking of the activation of the PI3K/Akt signaling pathway was similar to that of LY294002 treatment (Fig. 4).

\section{DISCUSSION}

In the current study STM treatment obviously reduced the number of TUNEL-positive cells in liver as compared with the $\mathrm{CCl}_{4}$ group. The mRNA expression of profibrotic genes such as TGF- $\beta 1$, collagen I, collagen III, CTGF, and fibronectin was inhibited with STM treatment as compared with the $\mathrm{CCl}_{4}$ group. The expression levels of $\mathrm{Bax}, \mathrm{Bcl}-2$, and cleaved caspase- 3 proteins were also significantly modulated by STM. Our data demonstrated that STM inhibited fibrosis-related factors in $\mathrm{CCl}_{4}$-induced liver injury and exerted a beneficial antiapoptotic effect.

TGF- $\beta 1$ is the most potent stimulus to the synthesis of fibrillar collagens and other matrix proteins [18]. It is believed that release of TGF- $\beta 1$ by necrotic hepatocytes may be one of the first signals to activate quiescent HSCs [19]. Activated HSCs show a sequence of fibrogenic properties, including proliferation and accumulation in areas of parenchymal cell necrosis, secretion of proinflammatory cytokines and chemokines, and production of ECM, leading to progressive scar formation [20]. In the current study, expression of TGF- $\beta 1$ mRNA was significantly upregulated following $\mathrm{CCl}_{4}$ administration. STM efficiently downregulated TGF- $\beta 1$ expression and repressed the activation of HSCs.

An imbalance between ECM degradation and production exists during hepatic fibrosis. The activation of HSCs leads to synthesis and secretion of a large number of fibril-forming collagens, especially collagen types I and III [21,22]. During hepatic fibrosis, the main components of the scar matrix are collagen types I and III, which replace the basal membrane of the subendothelial space of Disse and sinusoids $[23,24]$. In the current study, using real-time PCR, we found that expression of collagen types I and III mRNA was enhanced in $\mathrm{CCl}_{4}$-induced liver fibrosis, while abrogated by STM treatment; thus, STM significantly decreased the accumulation of ECM in liver tissues. CTGF, an important
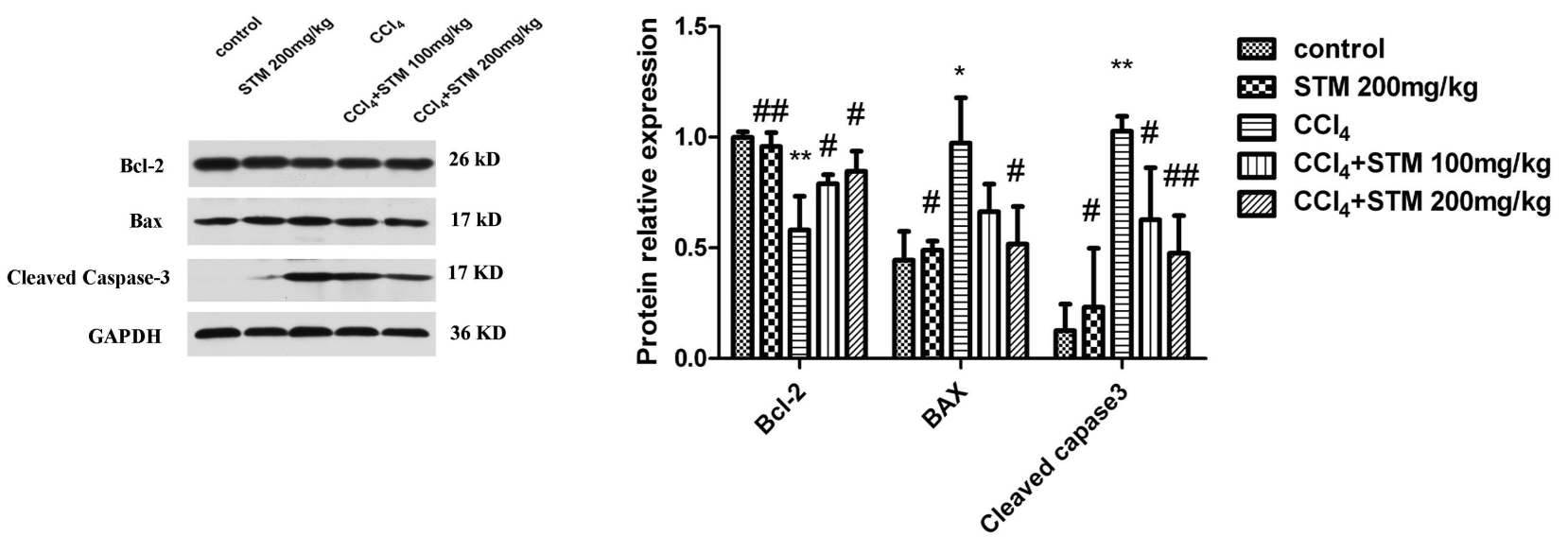

Fig. 3. Western blot assay of $\mathrm{BCl}-2$, Bax, and cleaved caspase-3 expression of livers in $\mathrm{CCl}_{4}$-induced rat liver. $\mathrm{CCl}_{4}$ treatment obviously suppressed the expression of $\mathrm{Bcl}-2$ compared with the control group. In $\mathrm{CCl}_{4}+\mathrm{STM}$ groups, $\mathrm{Bcl}-2$ protein levels were notably restored when compared with the $\mathrm{CCl}_{4}$ group. The expression of Bax and cleaved caspase-3 were induced following $\mathrm{CCl}_{4}$ treatment. STM markedly reduced the expression of Bax and cleaved caspase-3 compared with the $\mathrm{CCl}_{4}$ group. Data are represented as means \pm S.D. for 3-4 animals per group. ${ }^{*} \mathrm{p}<0.05$ vs. control, ${ }^{* *} \mathrm{p}<0.01$ vs. control; ${ }^{*} \mathrm{p}<0.05$ vs. $\mathrm{CCl}_{4},{ }^{\# \#} \mathrm{p}<0.01$ vs. $\mathrm{CCl}_{4}$ by one- way ANOVA and LSD post hoc test. 

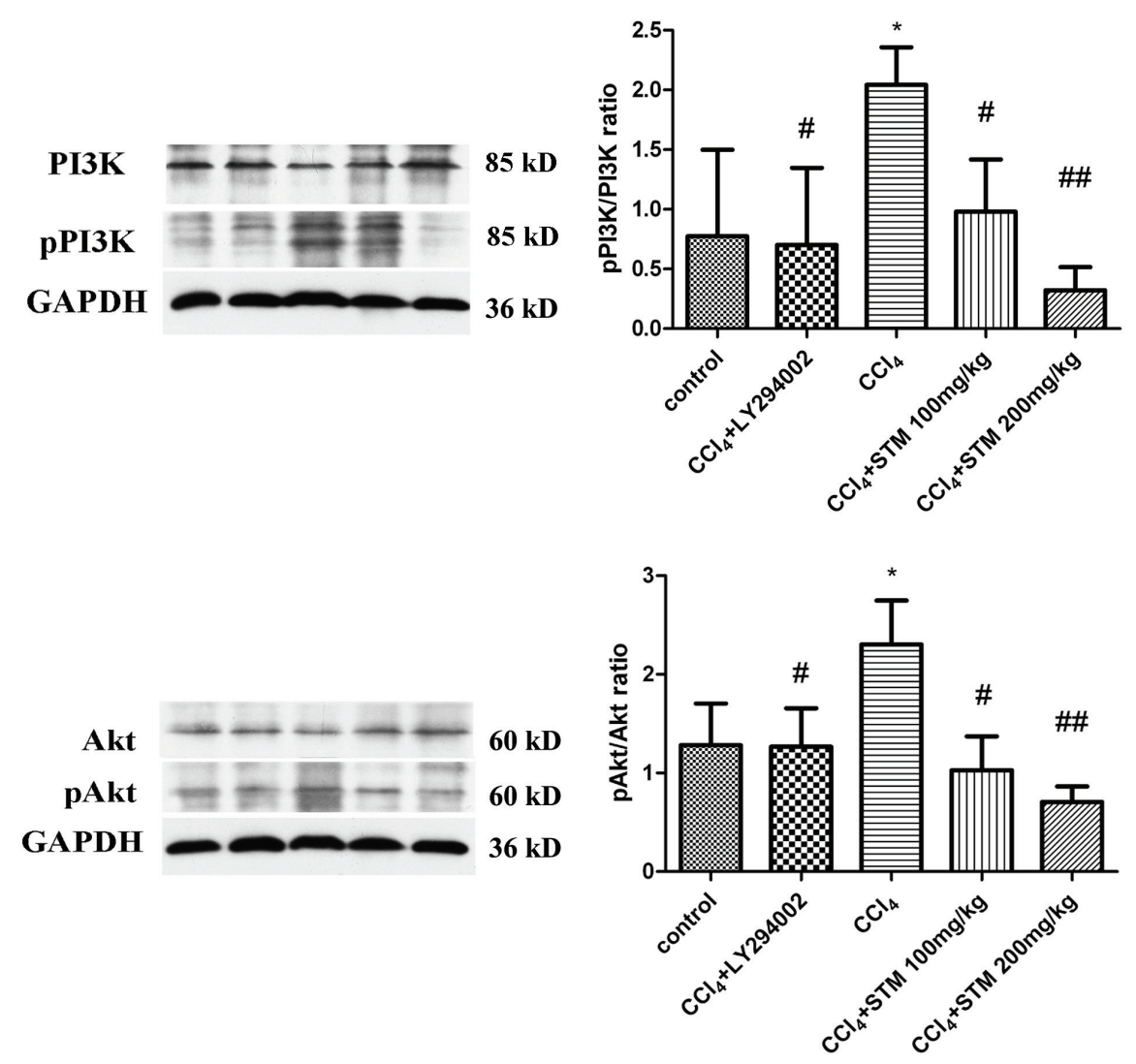

Fig. 4. STM inhibits hepatocyte apoptosis by blocking the activation of the PI3K/ Akt pathway. $\mathrm{CCl}_{4}$ treatment notably elevated the ratio of pAkt/Akt as compared with the control group. In addition, $\mathrm{CCl}_{4}$ treatment increased the ratio of pPI3K/PI3K as compared with the control group. In $\mathrm{CCl}_{4}+\mathrm{STM}$ groups, STM markedly reduced the expression of pAkt/Akt and pPI3K/PI3K as compared with the $\mathrm{CCl}_{4}$ group. Data are represented as means \pm S.D. for 3-4 animals per group. ${ }^{*} p<0.05$ vs. control, ${ }^{* *} p<0.01$ vs. control; $" \mathrm{p}<0.05$ vs. $\mathrm{CCl}_{4}, " \mathrm{p} p<0.01$ vs. $\mathrm{CCl}_{4}$ by one-way ANOVA and LSD post hoc test.

fibrogenic factor, is synthesized by hepatocytes and HSC mediating the interactions between fiber-fiber, fiber-matrix, and matrixmatrix. During liver fibrosis, CTGF is a hepatic fibrogenic master switch in the epithelial to mesenchymal transition, and plays a pivotal role in the increase of ECM-producing fibroblasts [25,26]. In the current study, expression of CTGF was upregulated in the $\mathrm{CCl}_{4}$-treated group, whereas STM treatment significantly alleviated this elevation. Fibronectin expression plays an important role during liver fibrosis. Its expression has been proved an early and progressive event that occurs during liver fibrogenesis in $\mathrm{CCl}_{4}$ induced liver fibrosis [27]. Our data indicated that STM inhibited fibronectin upregulation in $\mathrm{CCl}_{4}$-treated rats.

Hepatocyte apoptosis, a cardinal feature of many liver diseases, is considered to participate in initiating HSCs activation [28]. Apoptosis of parenchymal cells, an important inflammatory stimulus, activates HSCs, leading to the formation of fibrosis [29]. Thus, factors that affect hepatocyte apoptosis may be used to alleviate degree of fibrosis. In this study, DNA fragmentation of hepatocyte apoptosis was assessed using the TUNEL assay. In the $\mathrm{CCl}_{4}$-treated group, the number of TUNEL-positive cells was increased compared to the control group, whereas STM treatment significantly decreased the number of TUNEL-positive cells. However, the TUNEL assay is not a specific marker of apoptosis, thus western blotting was conducted to evaluate the effects of STM on the apoptotic pathway.

The mitochondrial apoptotic pathway is regulated by the Bcl-
2 family of proteins, which consists of both antiapoptotic (such as Bcl-2) and proapoptotic (such as Bax) proteins [30]. Activation of the proapoptotic Bcl-2 family of proteins such as Bax is known to play an important role in the oxidative stress-induced apoptosis [31]. It has been shown that Bax can translocate from the cytoplasm to mitochondria and exhibit conformational change under the apoptotic process. However, $\mathrm{Bcl}-2$ and $\mathrm{Bcl}-\mathrm{xL}$ prevent cytochrome $\mathrm{c}$ from entering the cytoplasm, either by blocking release or binding to the cytochrome in a direct or indirect fashion, and consequently inhibiting activation of the downstream caspase cascade [32]. Past reports have already demonstrated caspase-3 activation in $\mathrm{CCl}_{4}$-induced apoptotic hepatocytes [33,34]. In this study, we examined the levels of Bcl-2, Bax, and cleaved caspase-3 (an activated form of caspase-3) protein in liver tissue of apoptosis rats. Bcl-2 levels were significantly lowered in the $\mathrm{CCl}_{4}$ group than those in the control group. STM treatment significantly increased $\mathrm{Bcl}-2$ expression compared to that in the $\mathrm{CCl}_{4}$ group. Also, our data showed that Bax and cleaved caspase- 3 protein content was markedly increased in rats receiving $\mathrm{CCl}_{4}$ alone. Administration of STM effectively reduced the level of Bax and cleaved caspase-3 protein in rats exposed to $\mathrm{CCl}_{4}$. Our data indicated that STM significantly reduced $\mathrm{CCl}_{4}$-induced hepatic apoptosis in rats.

Our data also revealed that STM inhibited the PI3K/Akt signaling pathway by decreasing the ratio of pAkt /Akt and pPI3K/PI3K in $\mathrm{CCl}_{4}$-treated rat as similar with LY294002, a PI3K/Akt-specific inhibitor. The PI3K signaling pathway has been shown to regu- 
late procedures associated with HSCs activation such as collagen synthesis and cell proliferation in liver fibrosis [35]. The importance of PI3K signaling in the progression of hepatic fibrogenesis during HSC activation and profibrogenic mediator production has been demonstrated [36]. In the liver, PI3K activation could promote cytokine production and subsequent hepatocyte proliferation following partial hepatectomy [37]. In addition, PI3Kinduced Akt activation has been shown to significantly induce the proliferation and survival of HSCs, likely involving P70S6K activation [38]. Given the correlation between PI3K/Akt signaling and fibrosis, our results suggested that the antifibrotic effect of STM was related to the inhibition of the PI3K/Akt signaling pathway. However, the PI3K/Akt signaling pathway is involved in the apoptosis of hepatocytes. In ethanol-induced hepatocyte apoptosis, the PI3K/Akt pathway was significantly activated, and that could be reversed by LY294002 [39]. Our results illustrated that STM treatment conspicuously raised the Bcl-2 level, and efficaciously inhibited the expression and activation of caspase-3. The results demonstrated that the effect of STM inhibition of hepatocyte apoptosis induced by $\mathrm{CCl}_{4}$ was related to regulation of the PI3K/Akt signaling pathway.

In summary, this study showed that STM ameliorated $\mathrm{CCl}_{4}{ }^{-}$ induced hepatocyte apoptosis and hepatic stellate cell activation via blocking the PI3K/Akt signaling pathway in rats.

\section{CONFLICTS OF INTEREST}

The authors declare no conflicts of interest.

\section{REFERENCES}

1. Delire B, Stärkel P, Leclercq I. Animal models for fibrotic liver diseases: What we have, what we need, and what is under development. J Clin Transl Hepatol. 2015;3:53-66.

2. Liu T, Wang X, Karsdal MA, Leeming DJ, Genovese F. Molecular serum markers of liver fibrosis. Biomark Insights. 2012;7:105-117.

3. Cohen-Naftaly M, Friedman SL. Current status of novel antifibrotic therapies in patients with chronic liver disease. Therap Adv Gastroenterol. 2011;4:391-417.

4. Geerts A. History, heterogeneity, developmental biology, and functions of quiescent hepatic stellate cells. Semin Liver Dis. 2001;21:311335.

5. Cassiman D, Libbrecht L, Desmet V, Denef C, Roskams T. Hepatic stellate cell/myofibroblast subpopulations in fibrotic human and rat livers. J Hepatol. 2002;36:200-209.

6. Gomes LR, Terra LF, Wailemann RA, Labriola L, Sogayar MC. TGF- $\beta 1$ modulates the homeostasis between MMPs and MMP inhibitors through p38 MAPK and ERK1/2 in highly invasive breast cancer cells. BMC Cancer. 2012;12:26.

7. Liang B, Guo XL, Jin J, Ma YC, Feng ZQ. Glycyrrhizic acid inhibits apoptosis and fibrosis in carbon-tetrachloride-induced rat liver injury. World J Gastroenterol. 2015;21:5271-5280.
8. Lee TY, Chang HH, Wu MY, Lin HC. Yin-Chen-Hao-Tang ameliorates obstruction-induced hepatic apoptosis in rats. J Pharm Pharmacol. 2007;59:583-590.

9. Ravagnan L, Roumier T, Kroemer G. Mitochondria, the killer organelles and their weapons. JCell Physiol. 2002;192:131-137.

10. Zhang J, Dong M, Li L, Fan Y, Pathre P, Dong J, Lou D, Wells JM, Olivares-Villagómez D, Van Kaer L, Wang X, Xu M. Endonuclease $\mathrm{G}$ is required for early embryogenesis and normal apoptosis in mice. Proc Natl Acad Sci U S A. 2003;100:15782-15787.

11. Susin SA, Zamzami N, Kroemer G. Mitochondria as regulators of apoptosis: doubt no more. Biochim Biophys Acta. 1998;1366:151165.

12. Li P, Nijhawan D, Budihardjo I, Srinivasula SM, Ahmad M, Alnemri ES, Wang X. Cytochrome $\mathrm{c}$ and dATP-dependent formation of Apaf-1/caspase- 9 complex initiates an apoptotic protease cascade. Cell. 1997;91:479-489.

13. Lorenzo HK, Susin SA. Mitochondrial effectors in caspase-independent cell death. FEBS Lett. 2004;557:14-20.

14. Weber LW, Boll M, Stampfl A. Hepatotoxicity and mechanism of action of haloalkanes: carbon tetrachloride as a toxicological model. Crit Rev Toxicol. 2003;33:105-136.

15. Weiler-Normann C, Herkel J, Lohse AW. Mouse models of liver fibrosis. Z Gastroenterol. 2007;45:43-50.

16. Jaishree V, Badami S. Antioxidant and hepatoprotective effect of swertiamarin from Enicostemma axillare against D-galactosamine induced acute liver damage in rats. JEthnopharmacol. 2010;130:103106.

17. Wu T, Li J, Li Y, Song H. Antioxidant and hepatoprotective effect of swertiamarin on carbon tetrachloride-induced hepatotoxicity via the Nrf2/HO-1 pathway. Cell Physiol Biochem. 2017;41:2242-2254.

18. Lee YA, Wallace MC, Friedman SL. Pathobiology of liver fibrosis: a translational success story. Gut. 2015;64:830-841.

19. Liu X, Hu H, Yin JQ. Therapeutic strategies against TGF-beta signaling pathway in hepatic fibrosis. Liver Int. 2006;26:8-22.

20. Lotersztajn S, Julien B, Teixeira-Clerc F, Grenard P, Mallat A. Hepatic fibrosis: molecular mechanisms and drug targets. Annu Rev Pharmacol Toxicol. 2005;45:605-628.

21. Friedman SL. Liver fibrosis -- from bench to bedside. J Hepatol. 2003;38 Suppl 1:S38-53.

22. Schuppan D, Ruehl M, Somasundaram R, Hahn EG. Matrix as a modulator of hepatic fibrogenesis. Semin Liver Dis. 2001;21:351-372.

23. Rojkind M, Giambrone MA, Biempica L. Collagen types in normal and cirrhotic liver. Gastroenterology. 1979;76:710-719.

24. Nakatsukasa H, Nagy P, Evarts RP, Hsia CC, Marsden E, Thorgeirsson SS. Cellular distribution of transforming growth factor-beta 1 and procollagen types I, III, and IV transcripts in carbon tetrachloride-induced rat liver fibrosis. JClin Invest. 1990;85:1833-1843.

25. Gressner OA, Lahme B, Demirci I, Gressner AM, Weiskirchen R. Differential effects of TGF-beta on connective tissue growth factor (CTGF/CCN2) expression in hepatic stellate cells and hepatocytes. $J$ Hepatol. 2007;47:699-710.

26. Gressner OA, Gressner AM. Connective tissue growth factor: a fibrogenic master switch in fibrotic liver diseases. Liver Int. 2008;28: 1065-1079.

27. Liu XY, Liu RX, Hou F, Cui LJ, Li CY, Chi C, Yi E, Wen Y, Yin CH. Fibronectin expression is critical for liver fibrogenesis in vivo and in vitro. Mol Med Rep. 2016;14:3669-3675. 
28. Liu C, Wang G, Chen G, Mu Y, Zhang L, Hu X, Sun M, Liu C, Liu P. Huangqi decoction inhibits apoptosis and fibrosis, but promotes Kupffer cell activation in dimethylnitrosamine-induced rat liver fibrosis. BMC Complement Altern Med. 2012;12:51.

29. Friedman SL. Mechanisms of hepatic fibrogenesis. Gastroenterology. 2008;134:1655-1669.

30. Lee TY, Chang HH, Wang GJ, Chiu JH, Yang YY, Lin HC. Watersoluble extract of Salvia miltiorrhiza ameliorates carbon tetrachloride-mediated hepatic apoptosis in rats. J Pharm Pharmacol. 2006;58:659-665

31. Ding WX, Nam Ong C. Role of oxidative stress and mitochondrial changes in cyanobacteria-induced apoptosis and hepatotoxicity. FEMS Microbiol Lett. 2003;220:1-7.

32. Tien YC, Liao JC, Chiu CS, Huang TH, Huang CY, Chang WT, Peng WH. Esculetin ameliorates carbon tetrachloride-mediated hepatic apoptosis in rats. Int J Mol Sci. 2011;12:4053-4067.

33. Sun F, Hamagawa E, Tsutsui C, Ono Y, Ogiri Y, Kojo S. Evaluation of oxidative stress during apoptosis and necrosis caused by carbon tetrachloride in rat liver. Biochim Biophys Acta. 2001;1535:186-191.

34. Brown GC, Borutaite V. Nitric oxide, cytochrome c and mitochondria. Biochem Soc Symp. 1999;66:17-25.
35. Son MK, Ryu YL, Jung KH, Lee H, Lee HS, Yan HH, Park HJ, Ryu JK, Suh JK, Hong S, Hong SS. HS-173, a novel PI3K inhibitor, attenuates the activation of hepatic stellate cells in liver fibrosis. Sci Rep. 2013;3:3470.

36. Son G, Hines IN, Lindquist J, Schrum LW, Rippe RA. Inhibition of phosphatidylinositol 3-kinase signaling in hepatic stellate cells blocks the progression of hepatic fibrosis. Hepatology. 2009;50:15121523.

37. Jackson LN, Larson SD, Silva SR, Rychahou PG, Chen LA, Qiu S, Rajaraman S, Evers BM. PI3K/Akt activation is critical for early hepatic regeneration after partial hepatectomy. Am J Physiol Gastrointest Liver Physiol. 2008;294:G1401-1410.

38. Wang Q, Wen R, Lin Q, Wang N, Lu P, Zhu X. Wogonoside shows antifibrotic effects in an experimental regression model of hepatic fibrosis. Dig Dis Sci. 2015;60:3329-3339.

39. Chen X, Bian M, Zhang C, Kai J, Yao Z, Jin H, Lu C, Shao J, Chen A, Zhang F, Zheng S. Dihydroartemisinin inhibits ER stress-mediated mitochondrial pathway to attenuate hepatocyte lipoapoptosis via blocking the activation of the PI3K/Akt pathway. Biomed Pharmacother. 2018;97:975-984. 